\title{
NON-SURGICAL MANAGEMENT OF GINGIVAL OVERGROWTH CAUSED BY A COMBINATION OF TACROLIMUS AND AMLODIPINE IN A RENAL TRANSPLANT PATIENT- A RARE CASE REPORT
}

Anju Cecil'1, Shivaprasad Bilichodmath ${ }^{2}$

1 Postgraduate Student, Department of Periodontology, Rajarajeswari Dental College and Hospital, Bangalore, Karnataka, India. 2Professor, Department of Periodontology, Rajarajeswari Dental College and Hospital, Bangalore, Karnataka, India.

HOW TO CITE THIS ARTICLE: Cecil A, Bilichodmath S. Non-surgical management of gingival overgrowth caused by a combination of tacrolimus and amlodipine in a renal transplant patient- a rare case report. J. Evolution Med. Dent. Sci. 2018;7(29):3345-3347, DOI: $10.14260 /$ jemds/2018/754

\section{PRESENTATION OF CASE}

A 44-year-old male patient reported to the Department of Periodontology, Rajarajeswari Dental College and Hospital with a chief complaint of swollen gums in his upper and lower front and back tooth region since 1 year. Medical history revealed that the patient was hypertensive since 10 years and was taking Amlodipine (Amlong) $5 \mathrm{mg}$ twice daily. He also gave a history of renal transplant 6 years ago, after which he was under the following medications: Tacrolimus $0.5 \mathrm{mg}$ bid, Mycophenolate Mofetil (Mofetil) $500 \mathrm{mg}$ bid and Prednisolone (wysolone) $5 \mathrm{mg}$.

Intraoral examination revealed that there was diffuse bulbous enlargement of gingiva involving marginal, attached and interdental gingiva. The gingiva was erythematous with loss of stippling and bleeding on probing was seen (Figure 1 to 4). According to Clinical Index score as given by Ingles et al in 1999, the gingival enlargement was graded as Grade V. The oral hygiene status of the patient was fair. Complete haemogram revealed that all the blood parameters were in the normal range. Orthopantogram revealed there was generalised horizontal bone loss with respect to both maxillary and mandibular arch.

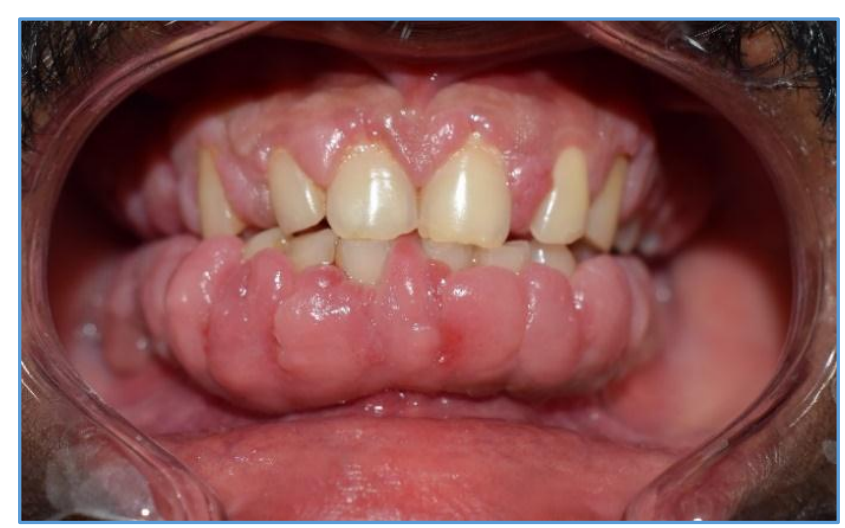

Figure 1. Preoperative- Frontal View

'Financial or Other Competing Interest': None.

Submission 05-06-2018, Peer Review 30-06-2018,

Acceptance 05-07-2018, Published 16-07-2018.

Corresponding Author:

Dr. Shivaprasad Bilichodmath,

Professor,

Department of Periodontology,

Rajarajeswari Dental College and Hospital,

Mysore Road

Kumbalgodu,

Bangalore-560074, Karnataka, India.

E-mail: drspmath@gmail.com

DOI: $10.14260 / j e m d s / 2018 / 754$

(c) $(i)(9)$

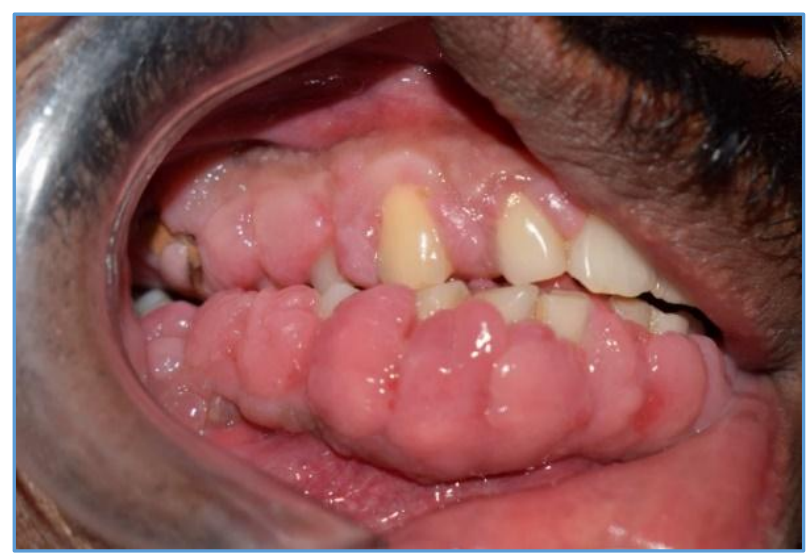

Figure 2. Preoperative- Right Lateral View

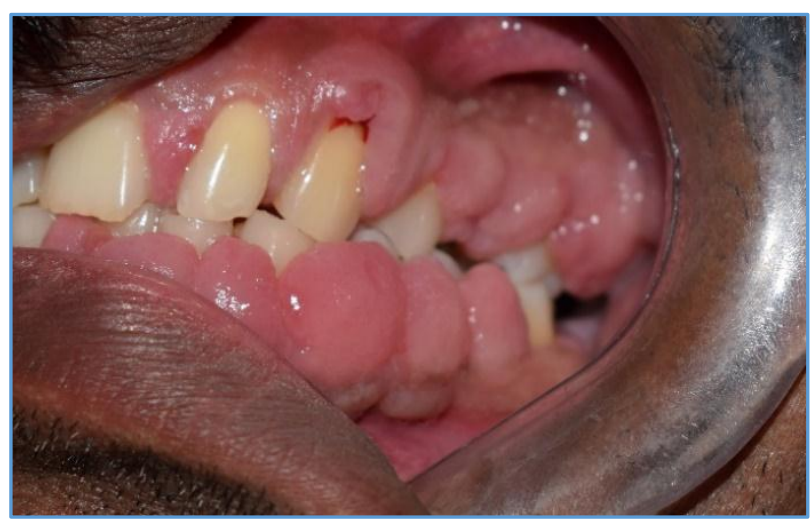

Figure 3. Preoperative-Left Lateral View

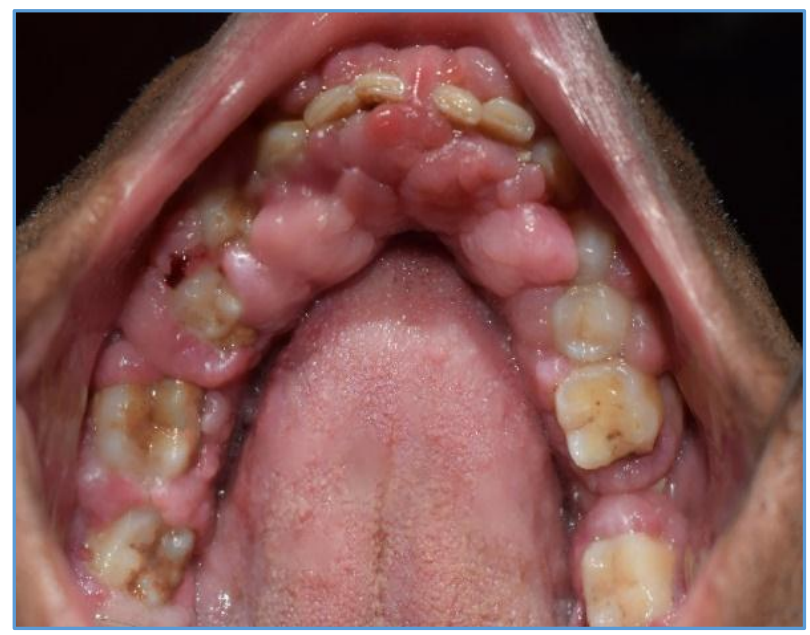

Figure 4. Preoperative-Mandibular Occlusal View

\section{DIFFERENTIAL DIAGNOSIS}

Inflammatory Gingival Enlargement. 


\section{CLINICAL DIAGNOSIS}

Drug-Induced Gingival Overgrowth.

\section{DISCUSSION OF MANAGEMENT}

Patient was referred to his physician for drug replacement and for opinion regarding scaling and root planing under local anaesthesia.

Amlodipine (Amlong) $5 \mathrm{mg}$ was substituted with Moxonidine (Moxovas) $0.2 \mathrm{mg}$ bid. Patient was also given Azithromycin $250 \mathrm{mg}$ for three days. A thorough scaling was done at the first visit. Patient was advised soft diet and meticulous oral hygiene practices including rinsing with chlorhexidine mouth rinse $0.2 \%$ twice daily and recalled after a period of 15 days.

After a period of 15 days, full mouth root planing was done, and oral hygiene instructions were given. Due to his compromised medical conditions, his physician did not give consent for surgical therapy. Non-surgical periodontal therapy was opted. Scaling and root planing were carried with a recall interval of 15 days between each visit.

A clinically significant reduction in gingival overgrowth was seen at the end of two months and grade of gingival enlargement was reduced to zero. Postoperative photographs were taken at the end of two months (Figure 5 to 8).

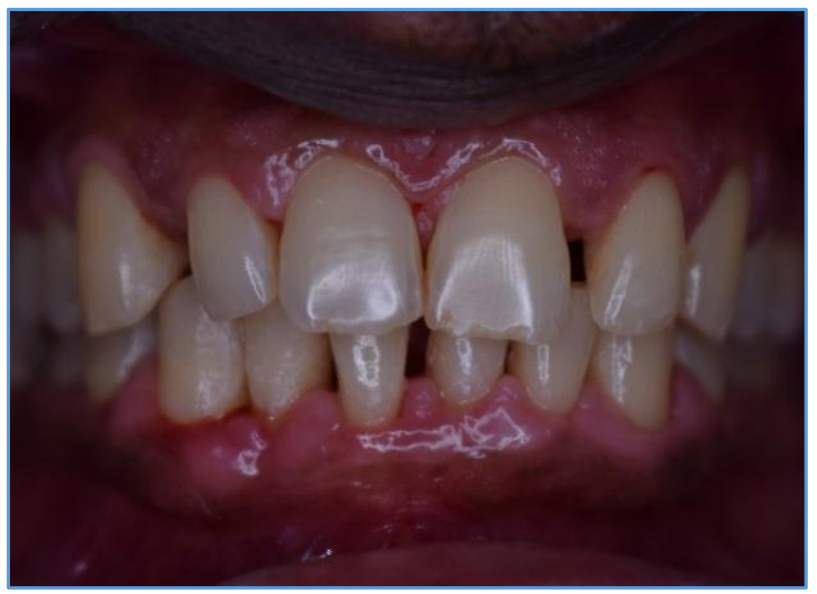

Figure 5. Postoperative- Frontal View

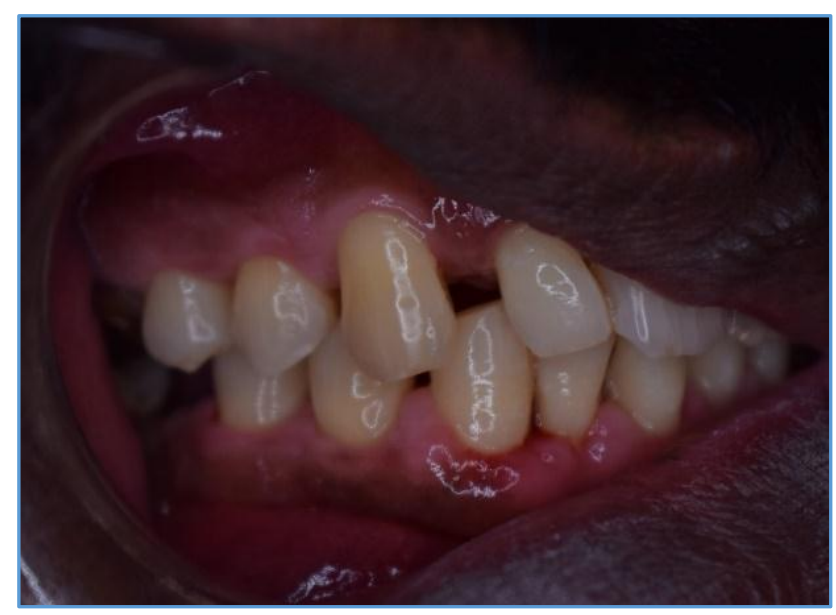

Figure 6. Postoperative- Right Lateral View

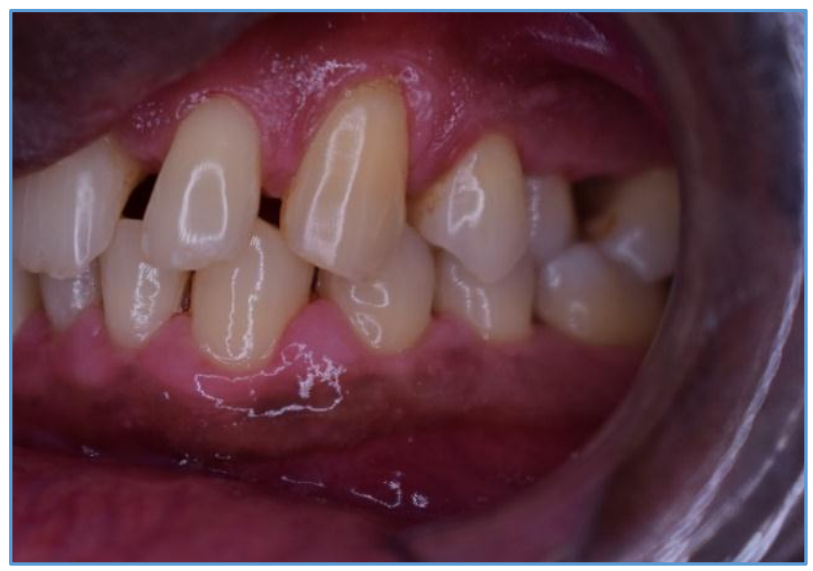

Figure 7. Postoperative- Left Lateral View

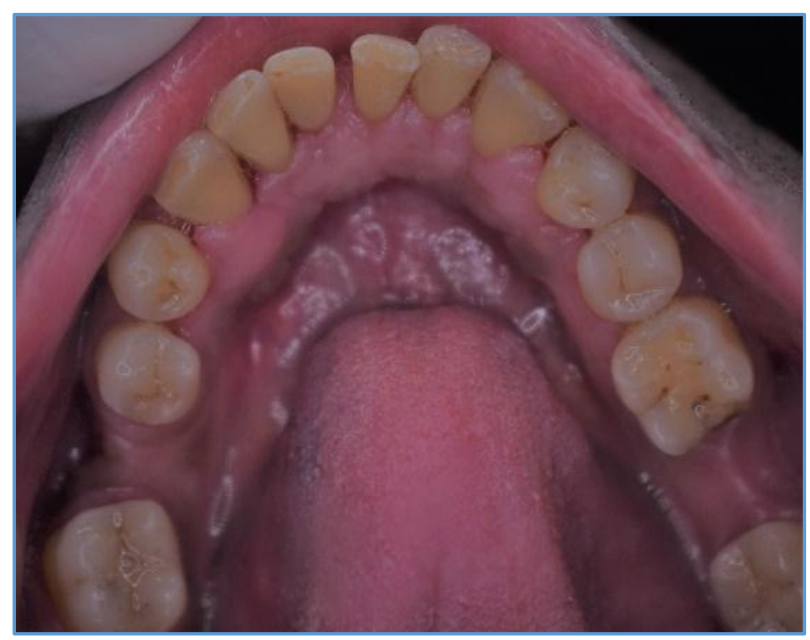

Figure 8. Postoperative-Mandibular Occlusal View

\section{PATHOLOGICAL DISCUSSION}

Long-term intake of three classes of drugs namely antiepileptics (Phenytoin), immunosuppressant (Cyclosporine A) and antihypertensive (Nifedipine, nitrendipine, felodipine, diltiazem, verapamil) are known to cause gingival overgrowth as an adverse effect. In patients taking a combination of cyclosporine and nifedipine, depending upon duration of intake of these drugs there is an increase in incidence and severity of gingival overgrowth. Other factors which contribute to the severity of gingival overgrowth are drug dosage, blood drug level, age, sex and pre-existing gingival inflammation. ${ }^{1}$ Seymour et al in 1994 reported the first case of drug-induced gingival overgrowth caused due to amlodipine, and dihydropyridine used for the treatment of hypertension and angina. ${ }^{2}$

Amlodipine is a second-generation dihydropyridine calcium channel blocker that can cause gingival hypertrophy. The prevalence of amlodipine-induced gingival hypertrophy has been shown to be between $1.7 \%$ and $3.3 \%$. Various theories have been proposed regarding the pathogenesis of gingival overgrowth. Two main inflammatory and noninflammatory pathways have been suggested. The noninflammatory mechanism includes defective collagenase activity due to decreased uptake of folic acid, blockage of aldosterone synthesis, in adrenal cortex and consequent feedback increase in the adrenocorticotropic hormone level and upregulation of keratinocyte growth factor. Alternatively, inflammation may develop as a result of direct toxic effects of 
concentrated drug in gingival crevicular fluid and/ or bacterial plaques. This inflammation could lead to the upregulation of several cytokine factors such as transforming growth factor-beta1 [TGF- $\beta 1] .^{3}$ Recent studies reveal that these drugs have a direct and indirect effects on the gingival fibroblast mechanism. Not all patients develop gingival overgrowth. Only a subset of patients develop abnormal susceptibility to the drug. ${ }^{4}$ Diagnosis is made depending on the medical history, clinical examination and histologic features. ${ }^{5}$

\section{Treatment Includes 6}

1. Drug withdrawal or substitution: But not all patients respond to this mode of treatment, especially those with long-standing gingival lesions.

2. Non-surgical treatment: Professional debridement with scaling and root planing as needed has been shown to offer some relief in gingival overgrowth patients.

3. Surgical treatment: The classical surgical approach has been the external bevel gingivectomy. However, a total or partial internal gingivectomy approach has been suggested as an alternative.

Gingival hypertrophy is 3.3 times more common in men than in women. ${ }^{3}$ It is also a well-known complication in $25 \%$ of renal transplant patients on cyclosporine. However, with tacrolimus, the occurrence is rare. Post-transplant gingival overgrowth can be effectively treated with a single course of azithromycin in almost all cases. Their efficacy can be due to an improvement in inflammation of the tissue alone. High azithromycin concentrations in human fibroblasts leads to the hypothesis of an interaction with endogenous growth factors and inflammatory mediators. ${ }^{7}$ In this case a course of azithromycin was given for a period of three days, which might have contributed in reducing inflammation.
Oral hygiene measures will reduce the local irritating factors, which will further lead to improvement in inflammation. After the inflammation has been considerably reduced, the remaining enlarged tissues are to be surgically excised to restore the normal morphology of the gingiva. But in this case, a complete reduction in the enlargement was seen with non-surgical periodontal therapy alone.

\section{FINAL DIAGNOSIS}

Drug-Induced Gingival Overgrowth.

\section{REFERENCES}

[1] Nishikawa S, Nagata T, Morisaki I, et al. Pathogenesis of drug-induced gingival overgrowth. A review of studies in the rat model. J Periodontol 1996;67(5):463-71.

[2] Seymour RA, Ellis JS, Thomason JM, et al. Amlodipine induced gingival overgrowth. J Clin Periodontal 1994;21(4):281-3.

[3] Madi M, Shetty SR, Babu SG, et al. Amlodipine-induced gingival hyperplasia-a case report and review. West Indian Med J 2015;64(3):279-82.

[4] Grover V, Kapoor A, Marya CM. Amlodipine induced gingival hyperplasia. J Oral Health Comm Dent 2007;1:19-22.

[5] Dhale RP, Phadnaik MB. Conservative management of amlodipine influenced gingival enlargement. J Indian Soc Periodontol 2009;13(1):41-3.

[6] Sharma NK, Roopa DA. Non-surgical management of amlodipine induced gingival enlargement - a case report. Int J Dental Sci Res 2014;2(6):137-40.

[7] Tokgöz B, Sari HI, Yildiz O, et al. Effects of azithromycin on cyclosporine-induced gingival hyperplasia in renal transplant patients. Transplant Proc 2004;36(9):2699-702. 